\title{
PERANCANGAN APLIKASI BROWSER PENCARIAN KEYWORD DENGAN MEMANFAATKAN FITUR SEARCH DI BERBAGAI WEBSITE MENGGUNAKAN METODE QUERY HASH JOIN PADA PERANGKAT ANDROID
}

\author{
Ari Kartanto Sinuhaji ${ }^{1}$, Yolanda Rumapea ${ }^{2}$, Darwis Robinson Manalu ${ }^{3}$ \\ Teknik Informatika, Fakultas Ilmu Komputer, Universitas Methodist Indonesia \\ Jl. Hang Tuah No.8 Medan 20152 \\ Telp (061) 4157882, Fax 62-61 4567533 \\ arikartanto27@gmail.com ${ }^{1}$, manaludarwis@gmail.com ${ }^{3}$
}

\begin{abstract}
The internet is a medium of information that is very fast and efficient in disseminating information that can not be separated by distance and time. To search for data through the website, sometimes the user forgets the address of the website to be search for data so that the data sought is difficult to obtain and if finally obtained, it takes a long time to find the data. Therefore a system is built that will facilitate the user in searching data without having to fill in the URL address of the search website, users can choose which websites will be used as a source of data search. Applications that are built using the hash join method where this method alone can be used to join tables containing website data in a database so that the user can display the desired data based on the input entered into the application. The results of the searches obtained are contents that contain texts in the form of titles or contents of web pages that match the keywords that users enter when searching from selected websites. This content can be in the form of web pages, which can then be accessed directly within the application.
\end{abstract}

Keywords: Hash Join, Join Table, Database, Keyword, Website, Application.

\section{PENDAHULUAN}

Pencarian secara digital menjadi bagian penting saat ini dalam memperoleh informasi dan data. Cara yang dilakukan adalah dengan mengunjungi situs (website) yang berhubungan dengan informasi yang dibutuhkan atau dengan lebih ringkasnya dapat dilakukan pencarian di situs pencari (Search Engine Sites).

Dalam mencari sebuah data lewat website sering sekali pengguna harus masuk terlebih dahulu ke sebuah alamat website untuk mencari data yang diinginkan. Terkadang pengguna lupa alamat lengkap URL dari website yang dicari sehingga data yang dicari sulit untuk didapatkan dan apabila akhirnya didapatkan membutuhkan waktu yang cukup lama untuk mencari data tersebut. Saat ini website search engine seperti Google memang mempermudah pengguna untuk mendapatkan data tertentu yang diinginkan oleh pengguna tetapi proses pencarian tidak langsung mengarah ke sumber website yang diinginkan.

Sebagai implementasi konkrit dari aplikasi yang dibangun adalah pengguna ingin mencari jurnal dari website portal garuda, pengguna ini sendiri tidak mengetahui alamat URL dari website portal garuda. Oleh karena itu sistem yang akan dibangun nantinya akan memfasilitasi pengguna dalam melakukan pencarian data tanpa harus mengisi alamat url dari sumber website yang akan dilakukan pencarian dan dari aplikasi yang akan dibangun pengguna dapat memilih website mana yang akan dijadikan sebagai sumber pencarian data.

Aplikasi yang dibangun menggunakan metode hash join dimana metode ini sendiri dapat digunakan untuk melakukan join table yang berisi data-data website pada database sehingga dapat ditampilkan data yang diinginkan pengguna berdasarkan input yang dimasukkan ke dalam aplikasi. Sehinga tujuan dari tulisan ini adalah merancang aplikasi browser pencarian keyword dengan memanfaatkan fitur search di berbagai website menggunakan metode query hash join pada perangkat android. Maka dapat mempercepat proses pencarian yang dilakukan oleh pengguna.

\section{LANDASAN TEORI}

\section{A. Aplikasi}

Aplikasi yaitu perangkat lunak yang digunakan untuk membantu pemakai komputer untuk melaksanakan pekerjaannya. Jika ingin mengembangkan program aplikasi sendiri, maka untuk menulis program aplikasi tersebut, dibutuhkan suatu bahasa pemrograman, yaitu language software, yang dapat berbentuk assembler, compiler ataupun interpreter. Jadi language software merupakan bahasanya dan program yang ditulis merupakan program aplikasinya. Language software berfungsi agar dapat menulis program dengan bahasa yang lebih mudah, dan akan menterjemahkannya ke dalam bahasa mesin supaya bisa dimengerti oleh komputer. Bila hendak mengembangkan suatu program aplikasi untuk memecahkan permasalahan yang besar dan rumit, maka supaya program aplikasi tersebut dapat berhasil dengan baik, maka dibutuhkan prosedur dan perencanaan yang baik dalam mengembangkannya

Sekarang, banyak sekali program-program aplikasi yang tersedia dalam bentuk paket-paket program. Ini adalah program-program aplikasi yang sudah ditulis oleh orang lain atau perusahaan-perusahaan perangkat lunak. Beberapa perusahaan perangkat lunak telah memproduksi paket-paket perangkat lunak yangmempunyai reputasi internasional. Program-program paket tersebut dapat diandalkan, dapat memenuhi kebutuhan pemakai, dirancang dengan baik, relatip bebas dari kesalahan-kesalahan, user friendly (mudah digunakan), mempunyai dokumentasi manual yang memadai, mampu dikembangkan untuk kebutuhan mendatang, dan didukung perkembangannya. Akan tetapi, bila permasalahannyabersifat khusus dan unik, sehingga tidak ada paket-paket program yang sesuai untuk digunakan, maka dengan terpaksa harus mengembangkan program aplikasi itu sendiri (Andi Juansyah,2015).

\section{B. Metode query Hash Join}

Query adalah semacam kemampuan untuk menampilkan suatu data dari database dimana mengambil dari tabel-tabel 
yang ada didatabase, namun tabel tersebut tidak semua ditampilkan sesuai yang diinginkan atau data yang ingin ditampilkan. Join table adalah penggabungan tabel-tabel menggunakan query yang dilakukan melalui kolom/key tertentu yang memiliki nilai terkait untuk mendapatkan satu set data dengan informasi lengkap. Lengkap disini artinya kolom data didapatkan dari kolom-kolom hasil join antar tabel tersebut. Join diperlukan karena perancangan tabel pada sistem transaksional kebanyakan dinormalisasi, salah satu alasannya untuk mengurangi redundansi (Junus Sinuraya, 2017) .

Hash join query digunakan untuk mengolah data yang berskala besar. Cara kerja hash join adalah membuat sebuah hash table berdasarkan predikat join. Setiap tabel yang memiliki inner atau outer dijadikan kode dangan hash function. Dari kode hash dari inner dan outer akan dibandingkan apabila kode kedua sama, maka dilakukan proses pengecekan nilai dalam kolom. Jika nilainya sama, maka akan dimasukkan kedalam hasil (Melany Mustika Dewi, 2017).

\section{ANALISIS DAN PERANCANGAN}

\section{A. Analisis Kebutuhan}

Untuk menyediakan aplikasi yang dapat memberikan informasi yang lengkap, maka dibutuhkan komponen penunjang didalam aplikasi.

1. Input Sistem
a. Input data website
b. Input data mengenai deskripsi website
c. Input data admin yang mengelola website pencarian
d. Input data member yang dimana member dapat menambah website pencarian
e. Input data kata kunci pencarian

2. Output Sistem
a. Menampilkan daftar website sumber pencarian
b. Informasi mengenai deskripsi website
c. Hasil pencarian dari sumber website yang diinginkan

\section{B. Perancangan Sistem \\ 1. Use Case Diagram}

Use case adalah kegiatan atau urutan interaksi yang saling berkaitan antara sistem dan aktor. Use case bekerja dengan cara mendeskripsikan tipe interaksi antara user sebuah sistem dengan sistemnya sendiri melalui sebuah cerita bagaimana sebuah sistem dipakai. Use case juga digunakan untuk membentuk perilaku (behaviour) sistem yang akan dibuat. Sebuah use case menggambarkan sebuah interkasi antara pengguna (aktor) dengan sistem yang ada. Berikut ini adalah use case diagram dari aplikasi yang akan dibangun :

\section{a. Use Case Diagram Admin}

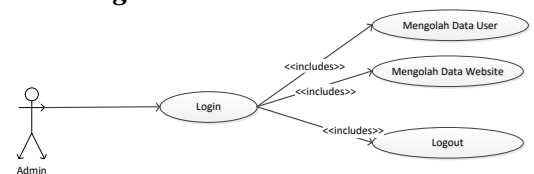

Gambar 1 Use Case Diagram Admin

\section{b. Use Case Diagram Pengguna}

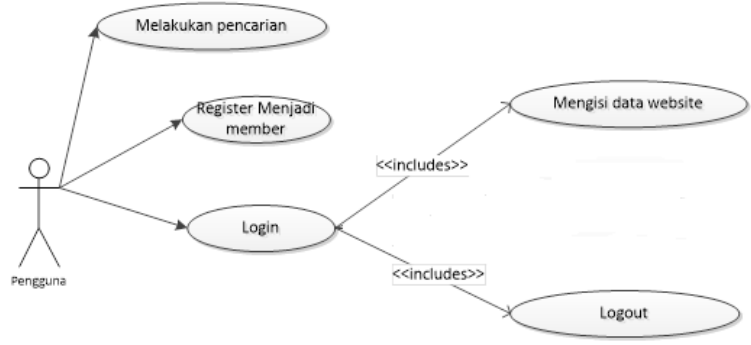

Gambar 2. Use Case Diagram Pengguna

\section{Activity Diagram}

Activity diagram digunakan untuk memodelkan atau menggambarkan suatu alur kerja sebuah proses dan urutan aktivitas pada suatu proses. Diagram ini dibuat untuk menggambarkan aktivitas dari actor. Activity diagram juga berguna untuk menggambarkan perilaku paralel atau menjelaskan bagaimana perilaku semua use case yang saling berinteraksi.

\section{a. Activity Diagram Akun Admin}

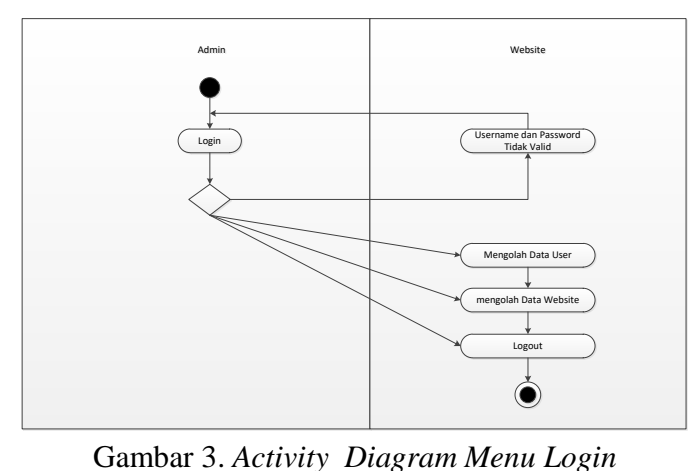

\section{b. Activity Diagram Kelola Data Admin}

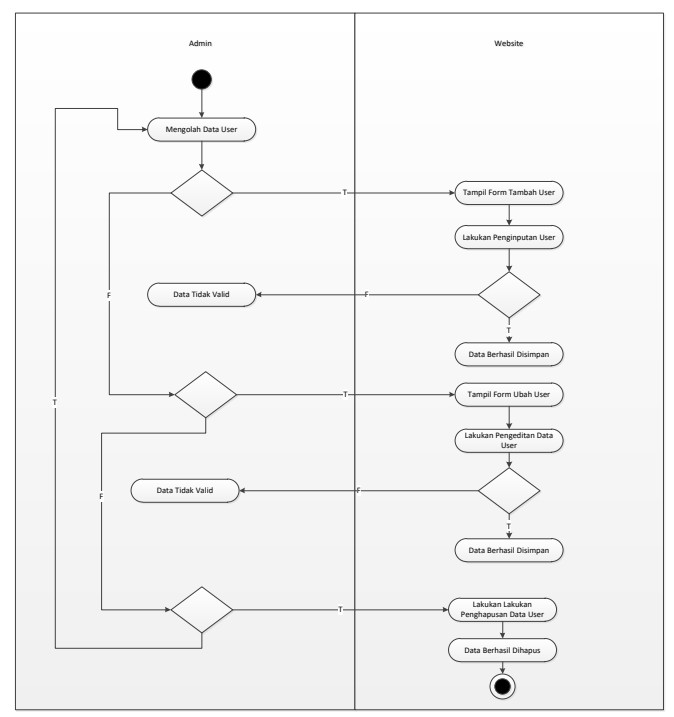

Gambar 4. Activity Diagram Kelola Data Admin 


\section{c. Activity Diagram Kelola Website}

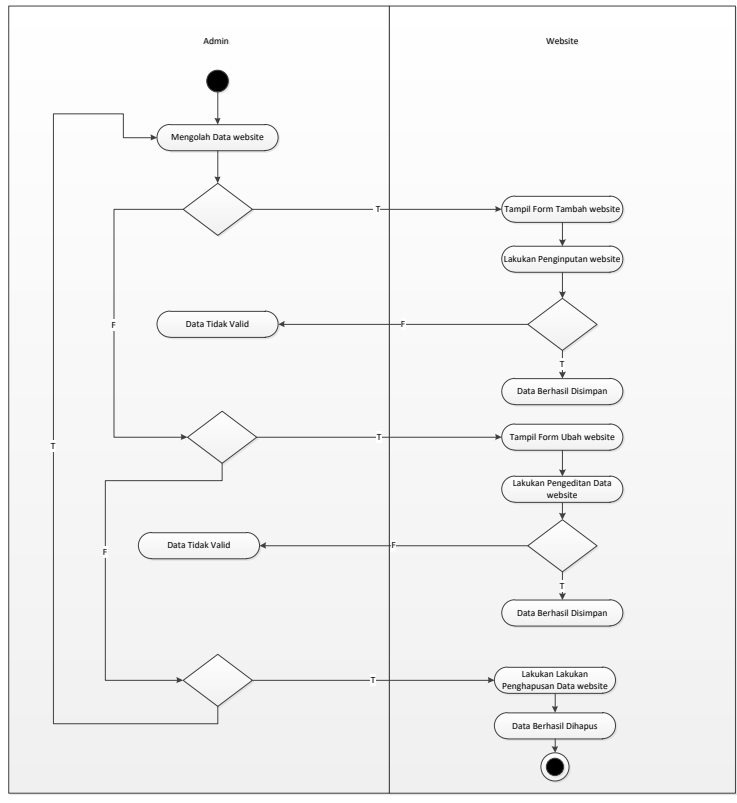

Gambar 5. Activity Diagram Kelola Data Website

d. Activity Diagram Register Pengguna di Android

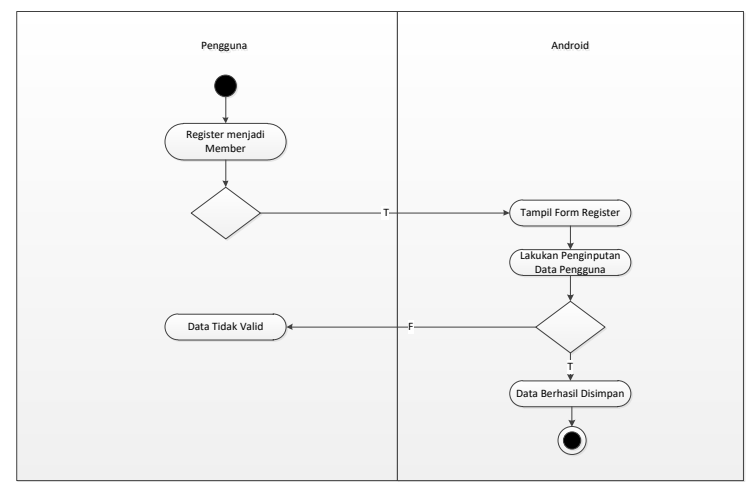

Gambar 6. Activity Diagram Register Pengguna di Android

\section{e. Activity Diagram Pencarian di Aplikasi Android}

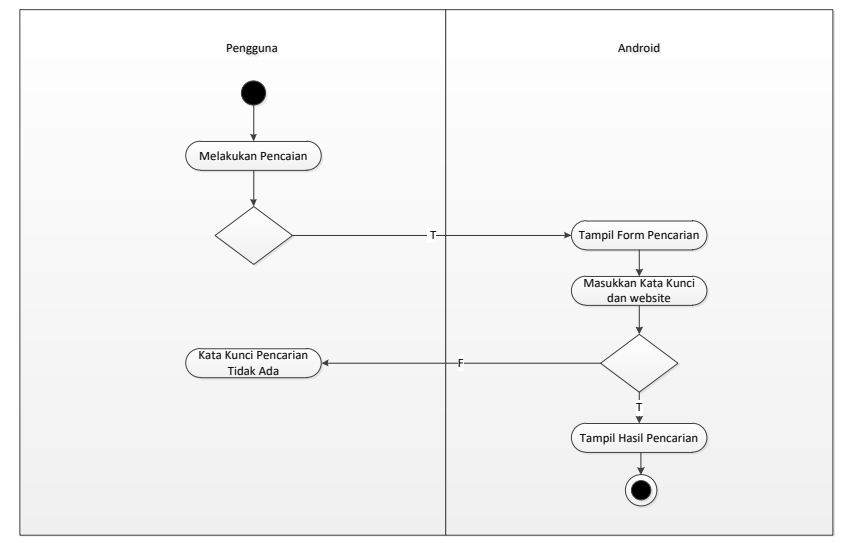

Gambar 7. Activity Diagram Pencarian di Aplikasi Android

\section{f. Activity Diagram Akun Member di Android}

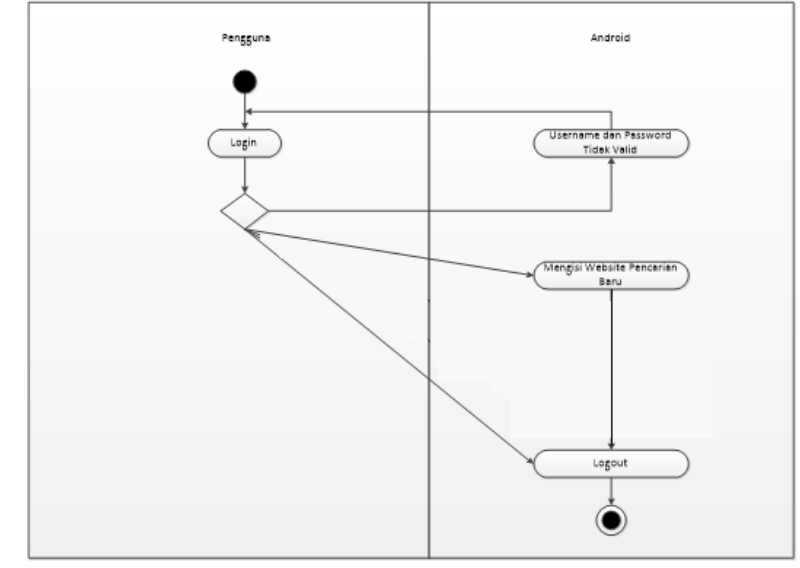

Gambar 8. Activity Diagram Akun Member di Android

\section{g. Activity Diagram Mengisi Website Baru Oleh Member}

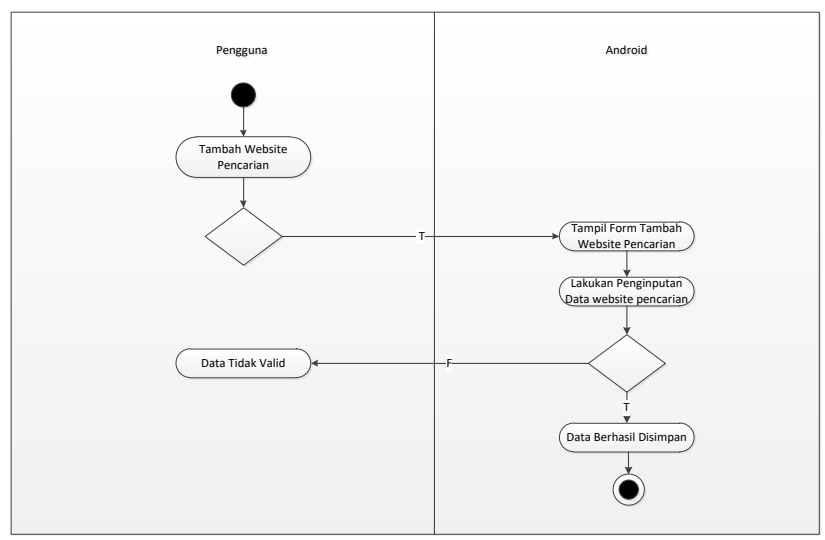

Gambar 9. Activity Diagram Mengisi Website Baru Oleh Member

\section{Sequence Diagram}

Sequence diagram digunakan untuk menggambarkan perilaku pada sebuah scenario. Diagram ini menunjukkan sejumlah contoh objek dan message (pesan)yang diletakkan diantara objek-objek di dalam use case. Sequence diagram secara grafis menggambarkan bagaimana objek berinteraksi dengan satu sama lain melalui pesan pada eksekusi sebuah use case atau operasi. Diagram ini mengilustrasikan bagaimana pesan terkirim dan diterima diantara objek dan dalam sekuensi apa.

\section{a. Sequence Diagram Login Admin}

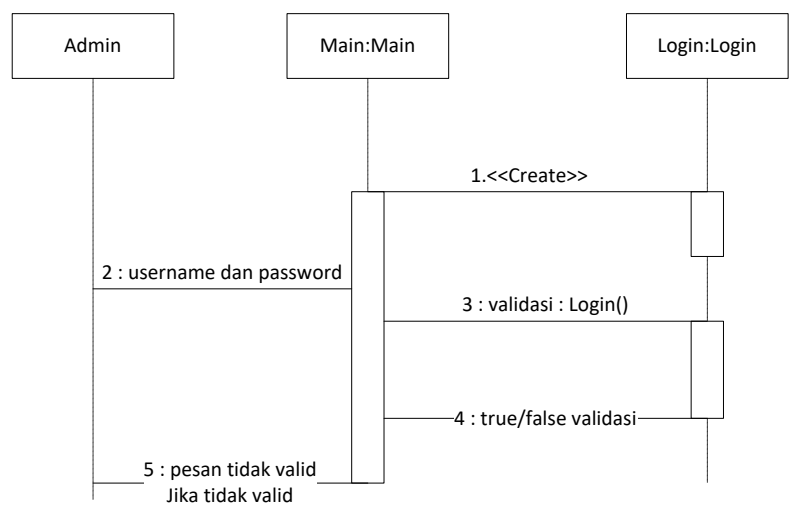

Gambar 10. Sequence Diagram Login Admin 


\section{b. Sequence Kelola Data Admin}

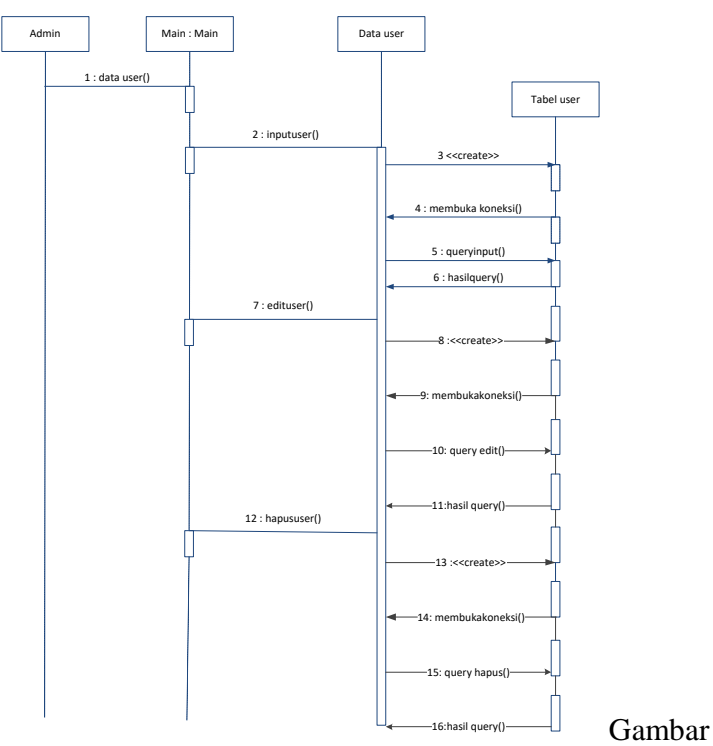

11. Sequence Diagram Kelola Data Admin

\section{c. Sequence Diagram Kelola Website}

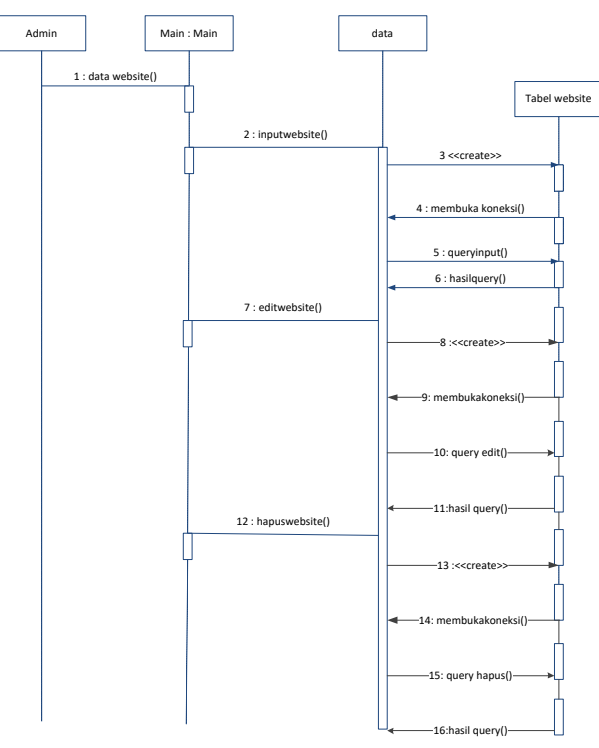

12. Sequence Diagram Kelola Data Website

\section{d. Sequence Diagram Register Member}

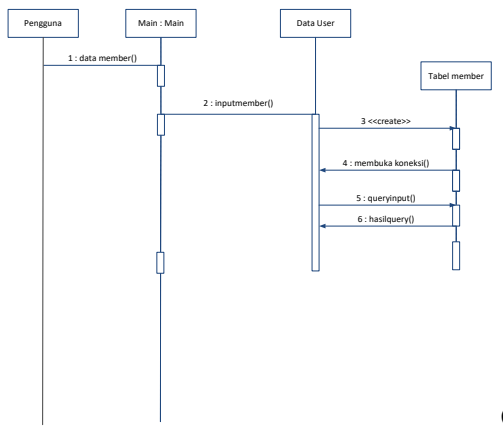

Gambar 13

Sequence Diagram Register Member e. Sequence Diagram Penambahan Website Pencarian Oleh Member

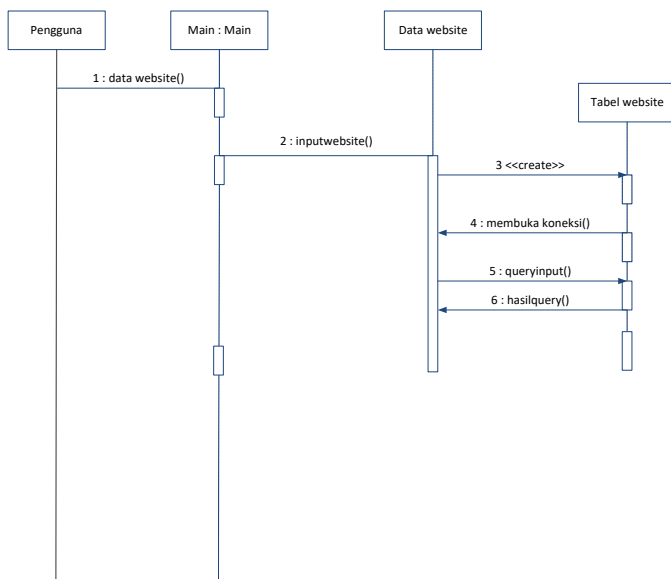

Gambar 14.Sequence Diagram Penambahan Website Oleh Member

\section{Class Diagram}

Class diagram adalah diagram yang digunakan untuk menampilkan beberapa kelas serta paket-paket yang ada dalam sistem/perangkat lunak yang sedang kita gunakan.

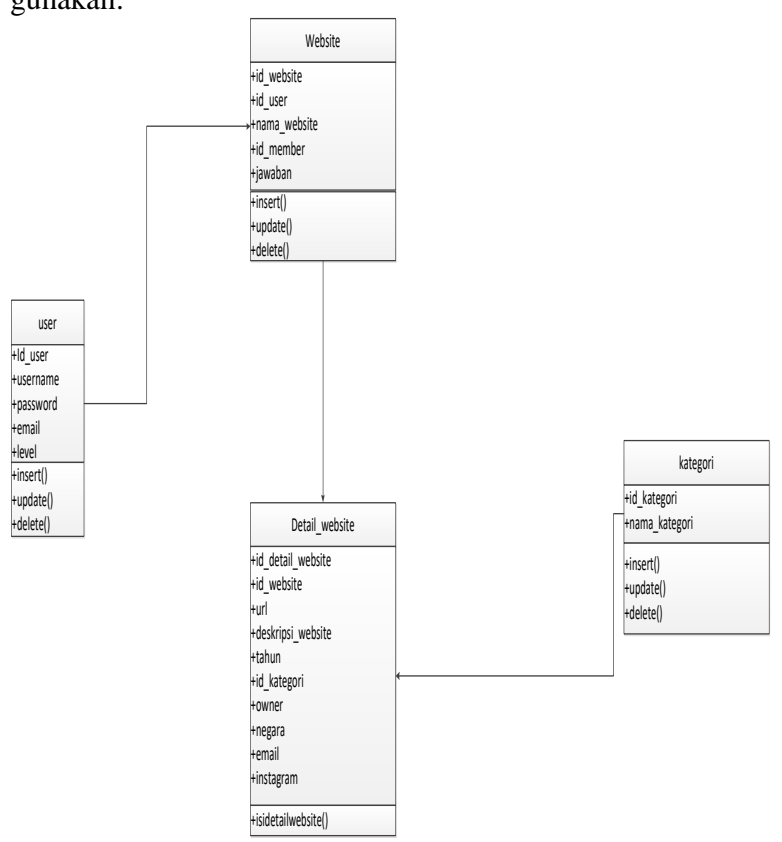

Gambar 15. Class Diagram

\section{Implementasi dan Pengujian Sistem}

\section{A. Pengertian Implementasi Sistem}

Setelah sistem dianalisis dan didesain secara rinci, maka akan menuju tahap implementasi. Implementasi sistem adalah langkah-langkah atau prosedur yang dilakukan dalam menyelesaikan desain system, menguji, dan memulai system baru yang telah disempurnakan. Implementasi bertujuan untuk mengkonfirmasi modul-modul perancangan, sehingga pengguna dapat memberi masukan kepada pengembangan sistem. 
B. Komponen Utama dalam Implementasi Sistem Agar sistem yang telah dikerjakan dapat berjalan baik atau tidak, maka perlu kiranya dilakukan pengujian terhadap sistem yang telah dikerjakan. Oleh karena itu, dibutuhkan beberapa komponen untuk mencakup perangkat keras (Hardware), perangkat lunak (software), dan perangkat manusia (Brainware).

\section{a. Perangkat Keras (Hardware)}

Hardware merupakan komponen yang terlihat secara fisik yang saling bekerja sama dalam pengolahan data. Perangkat keras yang digunakan meliputi:

a. Monitor

b. CPU (Central Processing Unit)

c. Hardisk sebagai tempat sistem beroperasi dalam media penyimpanan

d. Memori minimal $1 \mathrm{~GB}$

e. Keyboard dan Mouse

b. Perangkat Lunak (Software)

Software adalah instruksi atau program-program komputer yang dapat digunakan oleh komputer dengan memberikan fungsi serta penampilan yang diinginkan. Dalam hal ini perangkat lunak yang digunakan adalah:

a. Operating System Windows 10

b. Android Studio untuk membuat aplikasi android

c. Adobe Dreamwever CS5 sebagai tools editor untuk mendesain website

d. XAMPP 1.7.1 dimana terdapat Apache sebagai web server, PHP sebagai bahasa pemrograman yang digunakan, dan MySQL sebagai software untuk server database.

e. Google Chrome untuk menjalankan program web admin yang telah dirancang.

f. Minimum Android Jelly Bean 4.2 Untuk menjalankan aplikasi android

\section{c. Unsur Manusia (Brainware)}

Brainware merupakan faktor manusia yang menangani fasilitas komputer yang ada. Faktor manusia yang dimaksud adalah orang-orang yang memiliki bagian untuk menangani sistem dan merupkan unsur manusia yang meliputi:

a. System Analyst, yaitu orang membentuk dan membangun fasilitas tampilan sistem atau program.

b. Programmer, yaitu orang yang digunakan dalam membangun suatu program.

c. Operator (Administrator), yaitu orang yang mengoperasikan sistem seperti memasukkan data untuk dioperasikan oleh komputer dalam menghasilkan informasi dan lain sebagainya.

d. Public, yaitu orang yang memakai sistem yang telah dirancang untuk informasi yang dibutuhkan.

\section{Prototipe Aplikasi}

Berikut ini adalah tampilan program aplikasi android dan tampilan program website dari hasil desain program yang telah dibangun.

\section{Tampilan Menu Utama}

Tampilan menu utama berfungsi untuk menampilkan menu-menu yang terdapat pada aplikasi, menu utama berisi pilihan menu pencarian, tentang aplikasi, register dan login, jika pengguna telah login maka pada menu utama akan muncul pilihan menu beri saran yang berfungsi bagi member untuk memasukkan data website yang ingin ditambahkan. Tampilan Menu utama dapat dilihat pada gambar 4.2 .

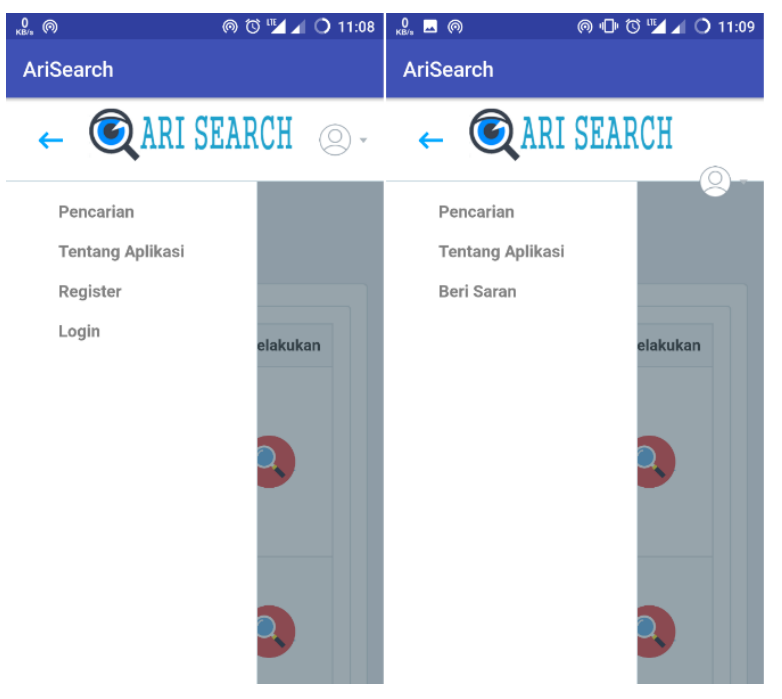

Gambar 16 Tampilan Menu Utama

\section{Tampilan Aplikasi Pencarian}

Tampilan aplikasi pencarian adalah tampilan yang akan digunakan pengguna untuk mencari data berdasarkan sumber pencarian dari website yang diinginkan. Tampilan aplikasi pencarian ini menampilkan nama sumber website, logo website, dan deskripsi website pencarian tersebut, selain itu terdapat juga kolom pencarian bagi pengguna dimana pengguna dapat mengisi kata pencarian (keywords) yang ingin dicari oleh member. Tampilan aplikasi pencarian dapat dilihat pada gambar 16 .

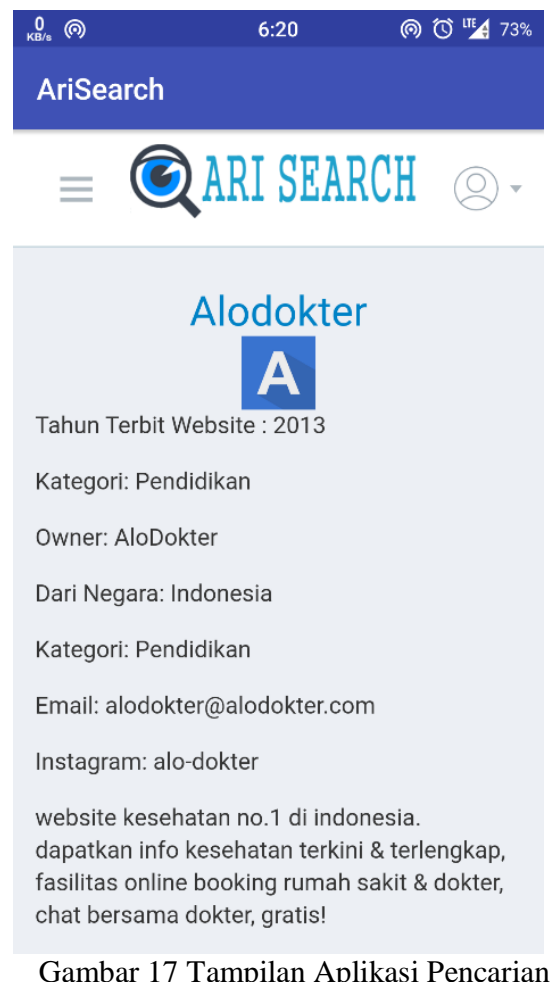

\section{Tampilan Hasil Pencarian}

Tampilan hasil pencarian adalah perancangan yang digunakan pengguna untuk mencari hasil pencarian berdasarkan kata kunci pencarian dan sumber website pencarian yang sudah diinput pengguna sebelumnya. Terdapat juga tombol drop menu untuk mengurutkan hasil 
pencarian berdasarkan relevansi dan tanggal, Tampilan hasil pencarian dapat dilihat pada gambar 7 .

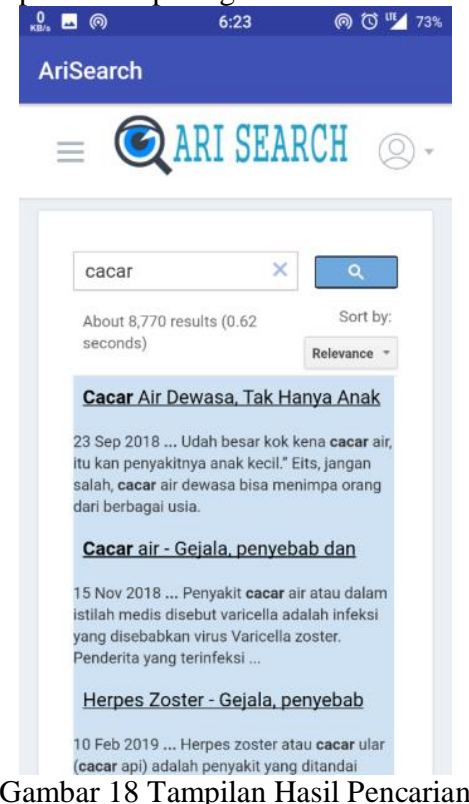

\section{Tampilan Data Website}

Tampilan menampilkan data website berfungsi bagi admin untuk menampilkan data admin yang sudah diinput di form website. Tampilan data website ini sendiri ditampilkan dalam bentuk tabel yang dimana kolom-kolom yang ditampilkan dalam bentuk tabel adalah kolom nama website, url, deskripsi website, logo website, dan kolom opsi apakah ingin mengubah data website atau menghapus data website. Tampilan output pengolahan data website dapat dilihat pada gambar 12 .

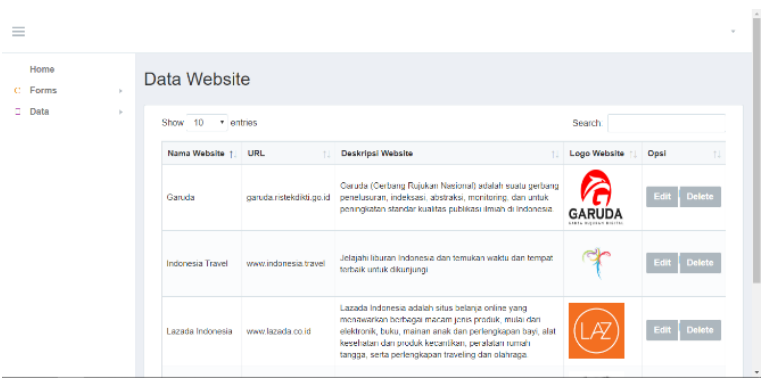

Gambar 19 Tampilan Data Website

\section{PENUTUP}

Sebagai kesimpulan dari hasil pembahasan dan pengujian antara lain:

1. Aplikasi yang dibangun dapat memudahkan pengguna dalam mencari suatu materi tanpa harus mengujungi website tertentu.

2. Metode Hash Join dapat membantu dalam proses pencarian karena dapat merelasikan antara dua tabel menjadi satu hubungan yang dapat menampilkan informasi yang lebih rinci pada saat proses pencarian.

3. Pengguna dapat menyarankan sumber website pencarian dengan mengisi di form saran website dan apabila admin menerima saran dari website yang disarankan pengguna maka sumber website pencarian akan tampil dalam aplikasi.
4. Dari hasil pengujian yang sudah dilakukan dapat dibandingkan bahwa metode hash join lebih cepat dari metode natural join dalam melakukan pencarian pada kasus penelitian kali ini.

\section{DAFTAR PUSTAKA}

[1] Ade Hendini. 2016. Pemodelan UML Sistem Informasi Monitoring Penjualan Dan Stok Barang (Studi Kasus: Distro Zhezha Pontianak). Jurnal Khatulistiwa Informatika, Vol. IV, No. 2 Desember 2016

[2] Andi Juansyah. 2015. Pembangunan Aplikasi Child Tracker Berbasis Assisted - Global Positioning System (A-Gps) Dengan Platform Android. Jurnal Ilmiah Komputer Dan Informatika (Komputa) Edisi 1. Volume 1. 1 Agustus 2015 Issn : 2089-9033

[3] Astria Firman. 2016. Sistem Informasi Perpustakaan Online Berbasis Web. E-Journal Teknik Elektro Dan Komputer Vol.5 No.2 Januari-Maret 2016, Issn 23018402

[4] Imaduddin Al Fikri. 2016. Aplikasi Navigasi Berbasis Perangkat Bergerak Dengan Menggunakan Platform Wikitude Untuk Studi Kasus Lingkungan ITS. Jurnal Teknik ITS Vol. 5, No. 1, (2016) Issn: 2337-3539 (2301-9271 Print)

[5] Indra Griha Tofik Isa. 2017. Implementasi Kansei Engineering Dalam Perancangan Desain Interface E-Learning Berbasis Web (Studi Kasus: Smk Negeri 1 Sukabumi). Jurnal Teknik Informatika Dan Sistem Informasi E-Issn : 2443-2229 Volume 3 Nomor 1 April 2017

[6] Indra Griha Tofik Isa. 2017. Perancangan Aplikasi Koperasi Simpan Pinjam Berbasis Web (Studi Kasus Koperasi Mitra Setia). [Issn 20886969] Vol. 5 Edisi 10, Mar 2017

[7] Junus Sinuraya. 2017. Metode Pencarian Data Menggunakan Query Hash Join dan Query Nested Join. Jurnal Teknovasi Volume 04, Nomor 01, 2017, 42-50 ISSN : 2355-701X

[8] Melany Mustika Dewi. 2017. Analisis Perbandingan Optimasi Query Nasted Join Dan Hash Join Pada Mysql Server. CSRID Journal, Vol.9 No.1 Februari 2017, Hal. 31-41 Issn: 2085-1367

[9] Putu Laxman Pendit, Ph.D. 2003. Penelitian Ilmu Perpustakaan dan Informasi : Suatu Pengantar Diskusi Epistemology dan Metodologi. Jakarta : JIPFSUI

[10] Septia Wulandari. 2013. Sistem Informasi CRM (Customer Relationship Management) Pada Cv.Indah Cemerlang Berbasis Website. Progam Studi Sistem Informasi, STMIK GI MDP, Palembang 